\title{
SYMPHONY OF COLORS IN PUBLICIST TEXSTS
}

\author{
Ioseb Sanikidze \\ Professor, Dr. of Philology \\ Batumi Shota Rustaveli State University
}

\begin{abstract}
The diversity of colors has a particular impact on human consciousness. The study deals with the study of the characteristic of the color palette, in both - the inner world of human nature and media texts. For this purpose, various publicist texts (informative, analytical and artistic-publicist) were discussed with student groups (200 students in total) and questionnaire has shown different colors perceived by them while acknowledging with the texts. The survey revealed that $57 \%$ of respondents saw a green color in informative texts, in the case of listening to analytical texts, $63 \%$ of the students saw a red color, while 53\% saw yellow color in the artistic-publicist texts.

Thus, when discussing publicistic material of different nature, a predominance of green, red, and yellow colors was revealed in students' perceptions. Such a vision of colors in publicism regulates and harmonizes the inner world of a human being; all of these are the best way to ascend to a higher level of life.

Key words: color palette, publicism, color perception, informative, analytical and artistic-publicist.
\end{abstract}

Introduction. Beauty, charm, attraction, exaltation naturally "flow" into the society, in a particular person as the nourishment of the soul, the expression of faith and hope. Such a pleasant fact or event in a person is perceived with certain colors in his association. There is a palette of natural, wonderful, multitude of colors in the world gifted by God that requires people to just enjoy it and perceive this beauty. Consequently, humanity has also created a multitude of colors in the history of its 
civilization, reflected not only in literature or painting, but also in architecture, painting, music or the visual representation of a man ... The eye perceives color, but the mind perceives it and conforms to personal "mood", approach, taste. Color, as one of the literal signs of human comprehension, is the natural constituent of every particular fact, and its neglect is equivalent to the death of the reflection of the given particular fact. Fresh, attractive colors always captivate not only the eyes of a man, but also his subconsciousness.

Color expression in the outlook of modern public thinking is clearly reflected in publicism. Every publicist text, as a concrete reality, a reflection of the exact facts of reality [1], carries a particular color. Every particular fact, event or process is represented by its own natural color, form and content, by time and space. Every journalist describing and expressing such facts or events uses some kinds of "color expression" characteristic to the certain individual [2]. Reasoning from the above mentioned, it is very interesting to "see" and perceive the colors in particular media contexts by the society, the mass audience, and the media users. It should be noted that in this regard there has not been fixed any in-depth research in the Georgian and foreign sources yet. However, we think there is a lot to be done in this direction. Modern publicism provides rich material for publicistic reflection on color expression, for investigating the impact of color on the mass audience, as a key characteristic of human aesthetic tastes of color. The present paper is concerned with the study of this problem and thus the research in this area is new and interesting.

Research aim, objects and methodology. The aim of the research was to present a color palette in the forms of publicist reflection, namely to give particular colors to particular publicist texts. In order to accomplish goal, we used a research method based on student groups, learning about the forms of publicist reflection of different kinds and inquiry. 
The study involved 200 students from the Faculty of Social Sciences of the Batumi Shota Rustaveli State University, who were given publicist texts (informative, analytical and artistic-publicist) and the research period lasted for a year. Having learnt the text, the students completed a questionnaire consisting of the following questions:

1. Which color dominates in the process of acquainting informative media texts?

a. red; b. yellow; c. green; d. other color ( name ------); e. no color

2. Which color dominates in the process of getting acquainted with media texts of an analytical nature?

a. yellow; b. green; c. red; d. other color ( name ------); e. no color

3. Which color dominates in the process of acquainting media-texts with artisticpublicist character?

a. green; b. red;c. yellow; d. other color ( name ------); e. no color.

Having acquainted the particular text each respondent (student) gave preference to his/her acceptable color. At the end of the research the results were summarized and processed by the method of statistical analysis.

Results. Surveys showed that the majority of the participant students, in particular, $57 \%$ gave a green color to informative texts. 15 percent of students saw red color in information and 12 percent perceived a yellow color. This is natural because the green color is associated with calmness and does not require in-depth analysis of the material. $16 \%$ of students perceived no color when discussing this publicity material.

When providing analytical texts to respondents, it was found that $63 \%$ preferred red. This is natural because the red color is strongly expressed; hence its interest is also sharp and high in charge. While discussing the analytical texts, $4 \%$ of respondents saw green, eight percent perceived yellow, five others (black, light blue, blue, purple), and 20\% of students did not perceive any color here.

When discussing artistic-publicist texts, $63 \%$ of students preferred yellow, green and red colors were perceived by nine and eight per cent, the rest - by 7 per cent, and 13 per 
cent did not see any color (see Table 1, Pic. 1, 2, 3). It should be assumed that the category of students who do not perceive a single color does not have adequate approach to the text.

Table 1. Color palette for student research

\begin{tabular}{|l|l|l|l|l|l|l|}
\hline Publicist texts & \multirow{2}{*}{$\begin{array}{l}\text { Number } \\
\text { of } \\
\text { participa } \\
\end{array}$} & \multicolumn{4}{|l|}{ Color palette perceived by students (\%) } \\
\cline { 3 - 7 } & green & red & yellow & $\begin{array}{l}\text { Other } \\
\text { colors }\end{array}$ & none \\
\hline Informative & 200 & $\begin{array}{l}57 \pm 3.5 \\
0\end{array}$ & $15 \pm 2.53$ & $12 \pm 2.30$ & 0 & $16 \pm 2.59$ \\
\hline Analytical & 200 & $4 \pm 1.38$ & $63 \pm 5.88$ & $8 \pm 1.92$ & $5 \pm 1.54$ & $20 \pm 2.83$ \\
\hline $\begin{array}{l}\text { Artistic- } \\
\text { publicist }\end{array}$ & 200 & $9 \pm 2.02$ & $8 \pm 1.92$ & $53 \pm 6.29$ & $7 \pm 1.64$ & $13 \pm 2.38$ \\
\hline
\end{tabular}

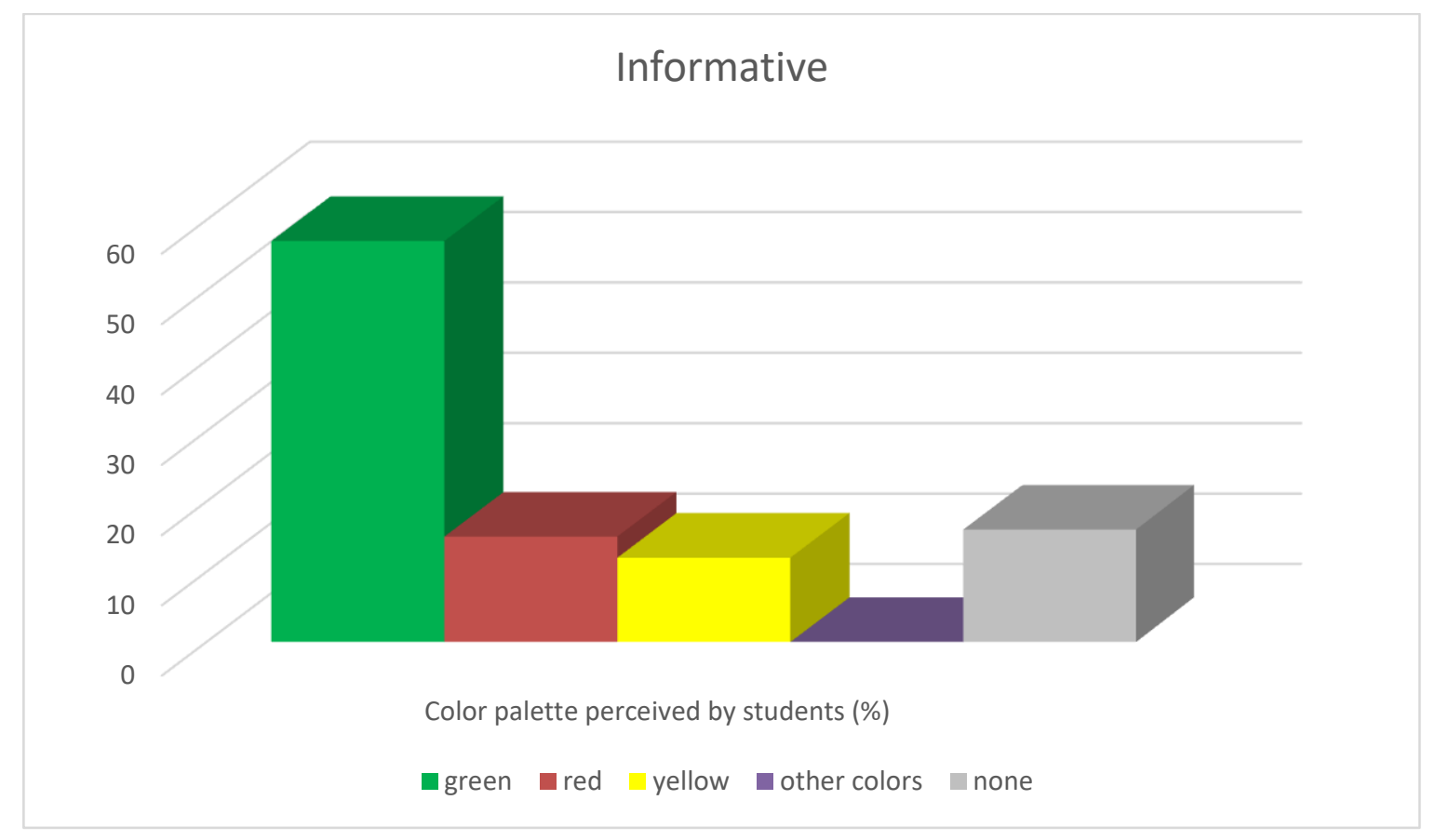

Picture1. Color palette for students when discussing informative texts 


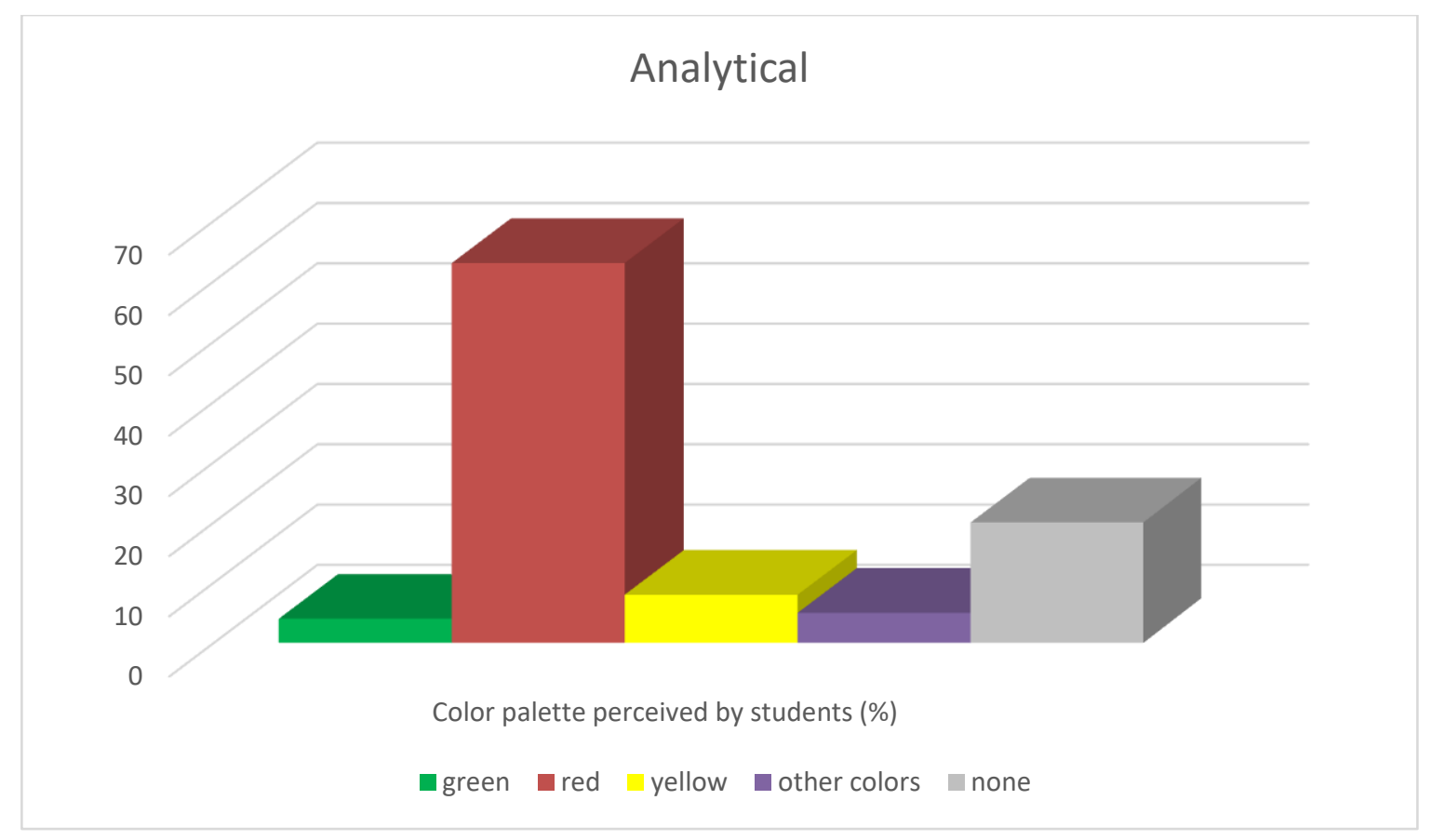

Picture2. Color palette for students when discussing analytical texts

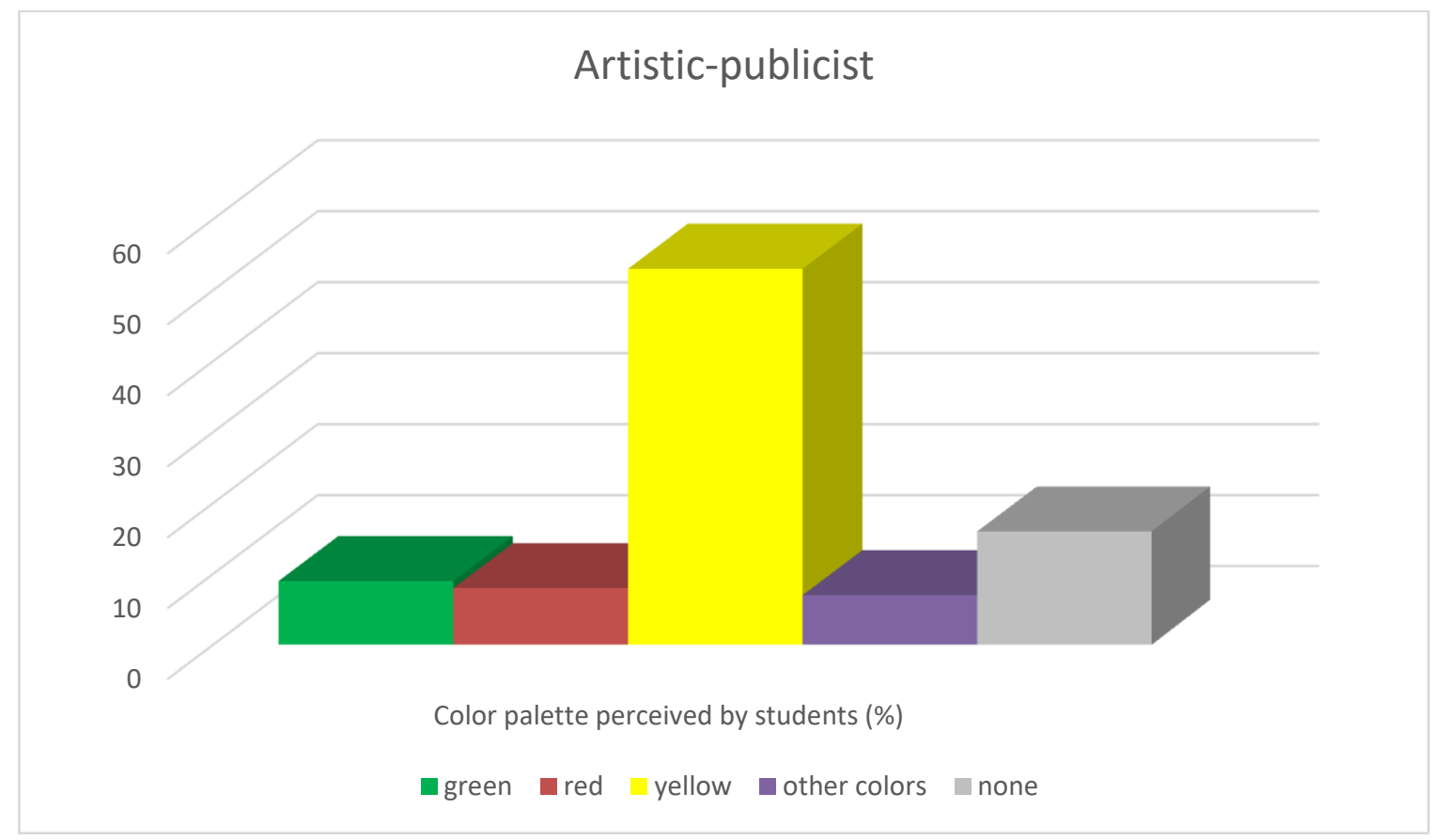

Picture3. Color palette for students when discussing artistic-publicist texts 
Discussion. It is interesting that the publicist fact is a specific reality, not an abstraction, an illusory imagination. So we should not be surprised by people's interest and passion in the news. As soon as we hear something new, our minds and memories immediately become strained of trying to catch sight of a particular novelty. To say briefly, not only the fact, but also the silhouettes and rustling of the bright colors of the fact, give a very special look and appeal to the subject of reflection, and the specific reflection is perceived by the appropriate reaction. The colors are so familiar to man, it's impossible to imagine life without them. It can be said that a person is wearing a particular color and emits his or her appropriate "flash". Our goal, too, was to show the beauty of color in media texts, which enhances and gives human nature the ability to sense beauty, love, kindness.

Research has also shown that the color palette, as well as the rhythm and melody, on the one hand makes the process of publicist reflection interesting, attractive, meaningful, dynamic and flexible; on the other hand, it helps the author to see, transmit, and enrich the auditorium better. At the same time it enriches aesthetical abilities that are the source of objectivity, impartiality and balance.

Conclusion. The process of discussing media texts, the "noticing" or perception of colors formed a number of specific aesthetic categories in students. The dominance of green, red and yellow was revealed in publicist works. In publicity, such a vision of color regulates and makes the human nervous system more harmonized, compatible, resistant, enduring, patient, finds expression in overcoming hatred, confrontation, intolerance, diversifies the skills of feeling of kindness, beauty, love, justice, objectivity, and impartiality in every member of society. All these are the best means of stepping on the highest level of life.

The color expression of modern media texts is a demonstration of reality, of specific real facts, which forms the basis for a systematic study of color as one of the important elements of a publicist structure. 


\section{References:}

1. Surguladze R. Basis of Journalistic studies: problems, main categories / Tbilisi, Nike, 1996. p. 234

2. Gersamia M. Elementary Particles in Journalistics: Text-book. Tbilisi, TSU, 2011, p. 104.

3. Sanikidze I. Formal and contextual foundations of journalism theory 2015, BSU, Universal, 2015. P.442. 